\title{
¿AUXILIARES E INTERMEDIARIOS? PIPAS DE FUMAR EN EL PIEDEMONTE DE JUJUY, ARGENTINA. ASOCIACIONES, CONTEXTOS E IMPLICANCIAS DISCURSIVAS
}

\author{
AUXILIARIES AND INTERMEDIARIES? SMOKING PIPES IN THEJUJUY \\ FOOTHILLS, ARGENTINA. ASSOCIATIONS, CONTEXTS AND DISCURSIVE \\ IMPLICATIONS
}

María Gabriela Ortiz ${ }^{A}$

\begin{abstract}
Las pipas de estilo San Francisco recuperadas en el piedemonte de Jujuy, Argentina, correspondientes al Período Formativo (2000 AP), presentan singulares diseños y tipos de manufactura que las distinguen de otras del NOA. Se conoce poco acerca de ellas debido a la carencia de datos certeros, obtenidos en condiciones controladas de excavación. Al ser objetos vinculados a prácticas asociadas al mundo de lo "no humano", se discuten las asociaciones contextuales de hallazgo, así como también los posibles discursos involucrados en su iconografía. Este enfoque partirá de la información etnográfica acerca de los modos de hacer en la práctica shamánica de las tierras bajas sudamericanas y la concepción emic por parte de estas poblaciones con respecto a la ontología de los objetos.

Palabras clave: Pipas, Tradición San Francisco, Formativo, Ontología de objetos.
\end{abstract}

The San Francisco-style pipes from the Formative Period (2000 BP) in the foothills of Jujuy, Argentina, show unique designs and types of manufacture which make them distinctive from other pipes in the northwest of Argentina. Little is known about them regarding because of the scarcity of accurate data obtained under controlled excavation conditions. As these are artifacts linked to practices associated with the "non-human" world here we discuss the contextual associations of find, as well as the possible discourses involved in its iconography. This approach builds on ethnographic information about the ways of doing in the shamanic practices in the South American lowlands and the emic conception of these populations about the ontology of objects.

Keywords: Pipes, San Francisco Tradition, Formative Period, Ontology of objects.
El mundo de los objetos, esa especie de libro donde toda cosa habla metafóricamente de todas las otras y en el que los niños aprenden a leer el mundo, se lee con todo el cuerpo, en y por los movimientos y desplazamientos que hacen el espacio de los objetos tanto como son hechos por él. Las estructuras que contribuyen a la construcción del mundo de los objetos se construyen en la práctica de un mundo de objetos construidos según las mismas estructuras

(Bourdieu 1980: 125).

\section{PRESENTACIÓN}

El consumo de psicotrópicos en América está ampliamente documentado desde épocas prehispánicas hasta el presente. Las formas en que fueron consumidos varían en el espacio y en el tiempo, y están en función del tipo de vegetal utilizado y, posiblemente, de los efectos deseados. Su uso por parte de poblaciones del noroeste de Argentina en épocas prehispánicas ha sido profusamente registrado a través de fuentes arqueológicas e históricas.

La forma de consumo más común y fehacientemente probada, desde al menos el Período Cazador-Recolector, fue la fumatoria, para la cual se utilizaban pipas de

A María Gabriela Ortiz, Unidad Ejecutora en Ciencias Sociales Regionales y Humanidades (CISOR), ConiCET, Universidad Nacional de Jujuy, Otero 262, San Salvador de Jujuy, CP 4600, Argentina. E-mail: yolatordo@hotmail.com 
cerámica, de hueso o de piedra (Fernández 1980). Tres pipas - una de hueso y dos de piedra- recuperadas en aleros con materiales arqueológicos y cronologías de esa época ( 2130 y $1430 \mathrm{AC})$ dieron positivo para alcaloides. En la pipa de hueso fue identificado uno de los alcaloides distintivos del cebil (5-hidroxi-dimethiltrytamina $[=\mathrm{Bu}-$ fotenina]) y en las pipas de piedra, ocho alcaloides de especies indeterminadas (Fernández 1980). Estos datos prueban que el consumo de sustancias psicotrópicas bajo la modalidad de fumado es una costumbre de larga data en el Noroeste Argentino, ya que las fechas establecidas para esos contextos corresponden a más de un milenio antes de Cristo. Por otra parte, la identificación positiva de cebil demuestra, además, que este vegetal fue uno de los más tempranamente utilizados y en esa época se encontraba circulando en esferas de intercambio muy extendidas. Entre las plantas más frecuentemente mencionadas en las fuentes escritas y reportadas en contextos arqueológicos se encuentran el cebil (Anadenanthera colubrina), el coro (Nicotiana paa) y el tabaco (Nicotiana tabacum/Nicotiana spp). Otras referencias están asociadas con plantas del género Brugmansia y Daturas (Pérez \& Gordillo 1995).

Sin embargo, es recién en el Período Formativo (800 AC-650 DC) cuando la costumbre del consumo en pipas muestra un inusitado auge. En casi todos los sitios arqueológicos de esa época se han encontrado estos artefactos, fabricados mayoritariamente de cerámica (Raffino 1977, Rosso \& Spano 2005-2006, Scattolin 2006, Fantuzzi 2008, Ledesma \& Subelza 2009, Bugliani et al. 2010).

Cada región se caracteriza por poseer distintos estilos de pipas. Algunas de las diferencias pueden deberse a elecciones estrictamente estilísticas y a su asociación con tradiciones alfareras particulares, pero en otros casos parecen depender de su desempeño, el efecto deseado y la modalidad de uso. No obstante, la popularidad de su empleo en momentos prehispánicos, muchas de las prácticas asociadas con la forma de uso de las pipas son desconocidas y, por lo tanto, supuestas y sin correlatos históricos, ya que desaparecen del registro arqueológico con posterioridad al Período Medio en el NOA. Sin embargo, en varios casos se pudo comprobar la presencia de sustancias específicas en su interior (Rosso \& Spano 2005-2006, Capparelli et al. 2006, Bugliani et al. 2010, Lema et al. 2015). En los datos históricos conocidos, solo se menciona su uso por parte de poblaciones del Chaco argentino, y mayoritariamente pipas de madera, aunque, en algunos casos excepcionales, también de cerámica
(Gonzalo 1998, Niklison 1990 [1916], Torres \& Repke 1996, Montani 2013, Alvarsson 2015). El tipo de pipas descritas corresponde a las denominadas tubulares, angulares y monitor (Gonzalo 1998).

Entre las sustancias consumidas se mencionan principalmente tabaco, coro y cebil. En el caso de este último, cuando se consume fumado es mezclado siempre con tabaco (Torres \& Repke 1996, Gonzalo 1998, Alvarsson 2015), preparado como un cigarrillo pequeño donde se envuelven las semillas y el tabaco en hojas, o en un blend usado en las pipas (Torres \& Repke 1996). Un caso poco usual lo constituye la ingesta de las semillas enteras, consumidas en situaciones excepcionales consideradas por los shamanes como de extrema gravedad o urgencia (Califano 1976).

En la región pedemontana de Jujuy ha sido reportada la mayor cantidad de estos artefactos (Serrano 1962, Dougherty 1975, Ortiz 2007). Aunque los hallazgos fueron dados a conocer desde principios del siglo $\mathrm{xx}$, no se tenía mayor información en relación con los contextos asociados, los vegetales consumidos, ni una descripción detallada de sus características tecno-morfodecorativas. La información es de suma importancia, pues permite avanzar en preguntas vinculadas a patrones de descarte, esferas de uso e interpretación de las posibles implicancias simbólicas y discursivas, incluyendo una ontología de los objetos rituales.

\section{SHAMANISMO, RITUALES Y ENTES AUXILIARES. HACIA UNA ONTOLOGÍA DE LOS OBJETOS}

Las diversas propuestas de los últimos años acerca de las nociones ontológicas que comparten muchas de las sociedades amerindias de Amazonía sobre las diferentes clases de seres, han sido especialmente descritas por etnógrafos como Descola (1986, 2012), Viveiros de Castro (2004) y Vilaça (2005), entre otros. Sin entrar en una discusión teórica o crítica sobre estos enunciados (Morales 2014, Reynoso 2015), resulta notable destacar que la etnografía del Chaco argentino identifica algunos principios análogos a los criterios ontológicos de muchos pueblos amazónicos. La noción común parece estar basada en que el mundo estaría habitado por diferentes tipos de humanidades, donde el cuerpo sería una especie de ropaje característico de cada especie, que envuelve componentes anímicos que los humanos comparten con 
ciertos animales, vegetales y dueños espirituales (Montani 2013). Las relaciones entre naturaleza y cultura serían reemplazadas por las interacciones entre humanos y no humanos, definiéndose recíproca y excluyentemente.

Estos principios son significativos al pensar el shamanismo amerindio. La práctica implica casi siempre el manejo del psicotropismo, lo que Ogalde (2007) denomina "praxis psicotrópica chamánica", que resulta en la construcción del vagomundo sagrado. Se logra tanto por una base empírica (manejo controlado de psicotrópicos) como por la construcción o existencia de una base teórica (uso de estructuras simbólicas específicas) (Ogalde 2007). Lo propio del shamán es hacer del estado alterado de conciencia un estado inteligible. Se aprende luego de años de aprendizaje ${ }^{1}$ y algo común a la iniciación shamánica es reconocer o aceptar "seres auxiliares" capaces de dotar de fuerza y sentido el viaje hacia el vagomundo. ${ }^{2}$ Los auxiliares, llamados a veces "amigos" del shamán, son tan importantes e imprescindibles como cualquiera de los objetos de la parafernalia o de las plantas usadas para inducir los estados alterados de conciencia.

La fuerza de un shamán reside más en la potencia, habilidad o experticia de los auxiliares que lo ayudan que en sus propias capacidades, aunque ambas están estrechamente vinculadas, pues alguien que pudo relacionarse con auxiliares poderosos evidencia un latente poder para ser un shamán eficaz. Los seres auxiliares acuden durante las sesiones shamánicas y son invocados tanto a través de una semántica específica como vehiculizados por diversos objetos.

¿Quiénes son los seres auxiliares? Gracias a la información etnográfica sabemos que se trata de diferentes clases de entes, tanto animales-humanos como espíritus o humanos no humanos que, de acuerdo con los principios ontológicos enunciados arriba, forman parte del universo (Chaumeil 2005, Descola 2005, Montani 2013). Solo el shamán puede reconocerlos e identificarlos, debido a ciertas conductas o corporalidades que lo alertan acerca de la particular esencia que los caracteriza. Dichas corporalidades suelen aparecer por primera vez durante la iniciación. Muchos de los seres auxiliares son incluso dueños de las plantas sagradas. La manera más común de vehiculizar su transposición es a través de objetos específicos, por ello tales objetos no son entes pasivos, sino que tienen una determinada agencia, vale decir, son sujetos socialmente actuantes (Bovisio 2012). Incluso, en el momento de la práctica dejan de ser referentes metafóricos para cobrar existencia, es decir, adquieren esencia y autonomía. Los objetos, al igual que los humanos, los animales y las plantas, tienen ontologías específicas (Descola 1986, Viveiros de Castro 2004, Flores \& Echazú 2016).

La parafernalia del shamán y las sustancias consumidas poseen capacidad de trasmutación al constituirse durante el acto ritual en objetos con propiedades exclusivas y alusivas a su esencia ontológica. En cualquier sesión de curación, el humo, por ejemplo, es un elemento vehiculador (Chaumeil 1998, Dasso \& Barúa 2006, Alvarsson 2015, Gili et al. 2017). Por eso, la forma de consumo que implica quemar alguna sustancia tiene tanta importancia para la trasmutación de su esencia como las propiedades enteógenas intrínsecas. ${ }^{3} \mathrm{Si}$ el ritual es aquella acción dirigida a agentes no humanos que tienen influencia en el destino humano, tal como lo expresan Nielsen et al., entonces los "rites and the archaeological contexts created by them afford an important opportunity for learning about the non-humans that inhabited the worlds of past peoples" (Nielsen et al. 2017: 242). Asimismo, la conducta ritual sirve para segregar ciertos lugares, personas y objetos a lo largo de historias de vida similares desde la creación hasta el descarte (Walker 1995). De acuerdo con Walker, los objetos rituales tendrían en común que: a) se encuentran restringidos al intercambio (singularidad); b) tienen historias de vida muy específicas y controladas; c) son frecuentemente descartados en contextos deposicionales discretos o singularizados; d) sirven como recursos materiales para tecnologías rituales y, e) ingresan frecuentemente al registro como basura ceremonial cuando han concluido su vida útil (no pueden cumplir sus funciones tecnológicas o ser reutilizados).

Identificar patrones repetitivos tanto en las cadenas de producción de los artefactos como en locus de descarte, podría dar indicios acerca de los objetos que pueden ser considerados sagrados, así como evaluar interacciones sociales vinculadas con ellos.

\section{LAS PIPAS DE LA TRADICIÓN SAN FRANCISCO}

Entre las pipas pertenecientes a poblaciones formativas del Noroeste Argentino, las conocidas más tempranamente son las adscritas a la denominada Tradición San Francisco (800 AC-500 DC, sensu Dougherty 1975). Por provenir de sitios arqueológicos ubicados en la vertiente 


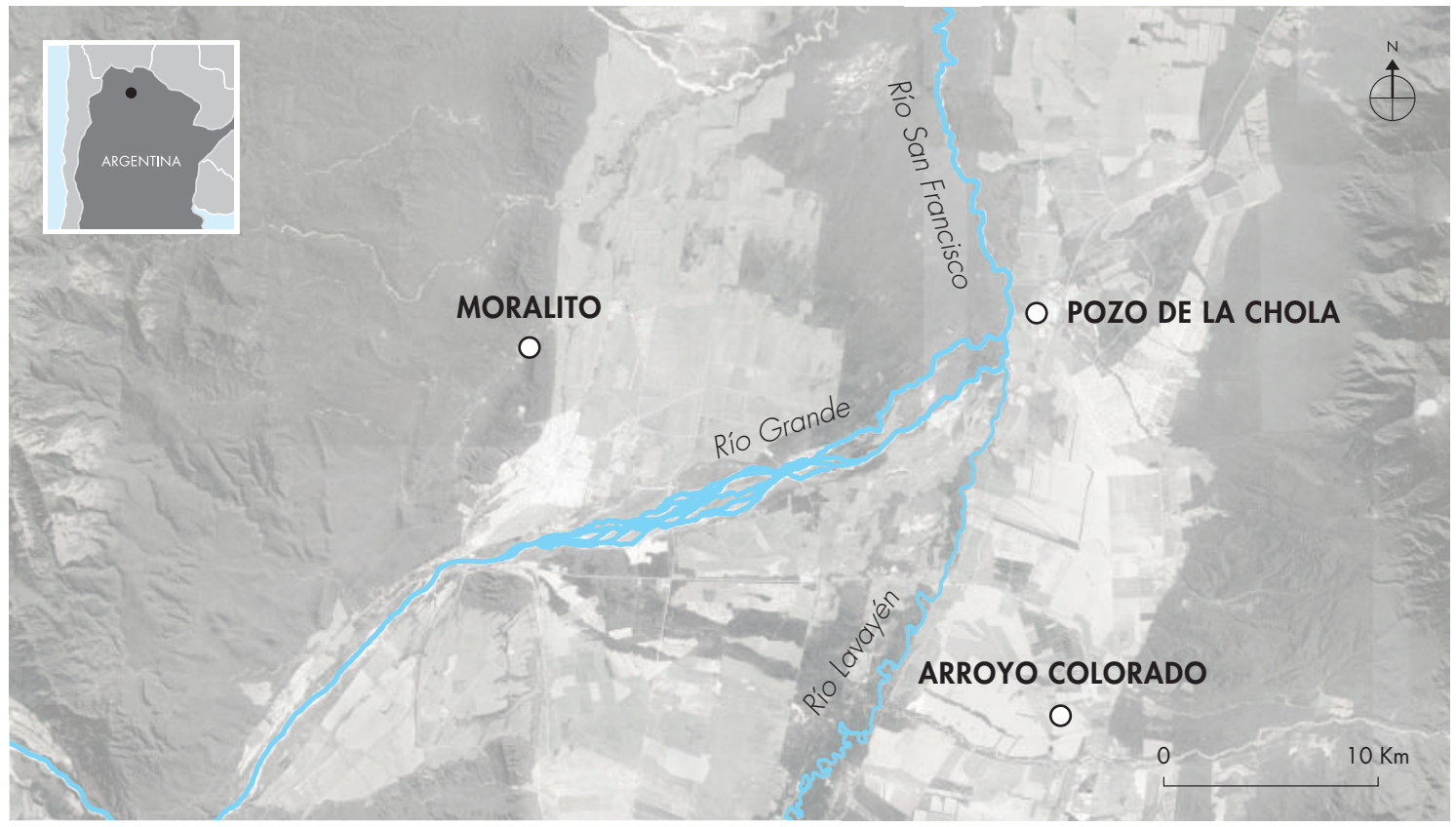

Figura 1. Localización de los sitios arqueológicos en la región del valle del río San Francisco: Pozo de la Chola, Moralito y Arroyo Colorado. Figure 1. Location of the archaeological sites in the San Francisco River valley Region: Pozo de la Chola, Moralito y Arroyo Colorado.

oriental de los Andes, se ha propuesto que la costumbre de fumar en estos artefactos fue difundida a través de la gran cuenca del Pilcomayo-Bermejo, y que los ríos Pasaje-Juramento favorecieron esta dispersión (Dougherty 1975, Pérez \& Gordillo 1995).

Los sitios arqueológicos vinculados a esta tradición son unicomponentes y poseen un patrón de asentamiento determinado por la orientación fluvial. Ocupan principalmente el piso altitudinal correspondiente a la selva pedemontana de las yungas del Noroeste Argentino y los fondos de valles en la actual Provincia de Jujuy (Argentina), particularmente en el valle de San Francisco (fig. 1), aunque se conocen otros sitios ubicados fuera de este lugar (Ortiz 2015). El valle se caracteriza por una vegetación chaqueña donde abundan los árboles de cebil.

Las pipas pueden encontrarse en todos los sitios arqueológicos; sin embargo, son muy escasas o ambiguas las referencias sobre los contextos de hallazgos para los casos publicados. En Saladillo Redondo se recuperaron fragmentos con una cronología asociada de 400 AC (Dougherty 1975, Ortiz 2003 para fechas calibradas). En el sitio Moralito, las dataciones realizadas al residuo carbonizado de dos hornillos de pipas arrojaron fechas de $1860 \pm 60$ y $1870 \pm 40$ AP (Echenique \& Kulemeyer
2003). En el sitio Pozo de la Chola se han recuperado hasta el momento un ejemplar completo y fragmentos de otros ocho artefactos. La cronología establecida para este último sitio, sobre la base de nueve fechados radiocarbónicos calibrados, data desde principios de la era cristiana hasta el 500 DC (Ortiz et al. 2018). Gracias a los trabajos de excavación sistemática realizados hasta el momento en Pozo de la Chola y los datos publicados para el sitio Moralito podemos discutir por primera vez la asociación contextual para esta clase de artefactos.

Pipas completas y ejemplares rotos aparecen en los sitios arqueológicos, de los que tenemos suficiente información espacialmente sectorizada. Muy infrecuentemente algunos fragmentos pueden encontrarse mezclados entre los desechos de basura de facto. En el sitio Pozo de la Chola, la única pipa que pudo ser remontada completa, así como los fragmentos de otros ocho ejemplares incompletos de cerámica, fueron recuperados sobre un piso próximo a un gran fogón en cubeta en un solo sector del sitio. Esto a pesar de que se ha excavado un total de $108 \mathrm{~m}^{2}$ distribuidos en cuatro lugares diferentes de la superficie estimada de ocupación, la que abarca aproximadamente 2,5 ha (fig. 2). Hay que destacar que en el fogón se recuperaron restos humanos quemados incompletos, los que incluyen tres clases etarias (adulto, 

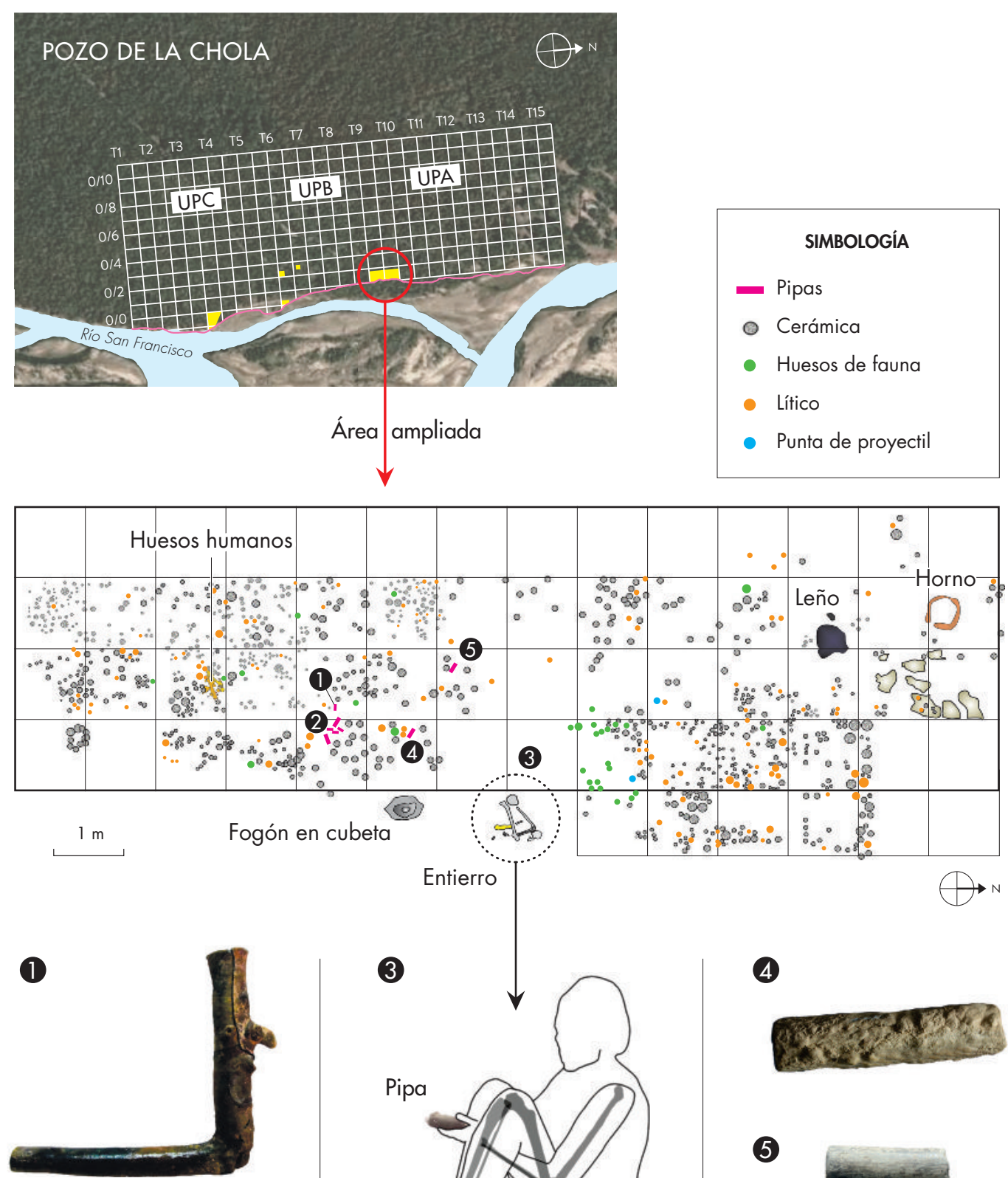

3

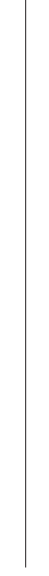

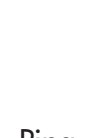

Pipa

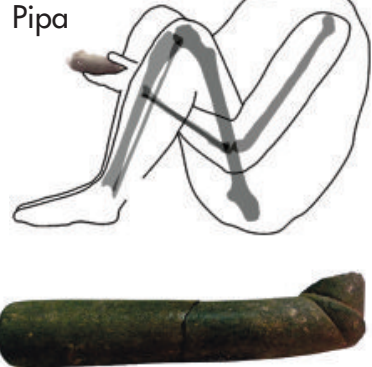

$10 \mathrm{~cm}$
(4)

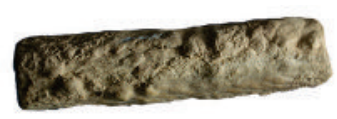

5
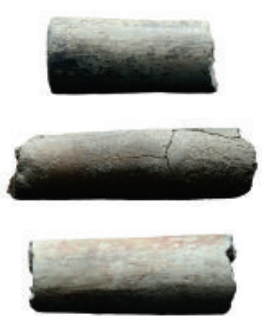

Figura 2. Ampliación del área de excavación del sector A del sitio Pozo de la Chola. Se indica la ubicación de los hallazgos. Figure 2. Enlargement of the excavation area of sector $A$ of the Pozo de la Chola site. The location of the findings is indicated. 


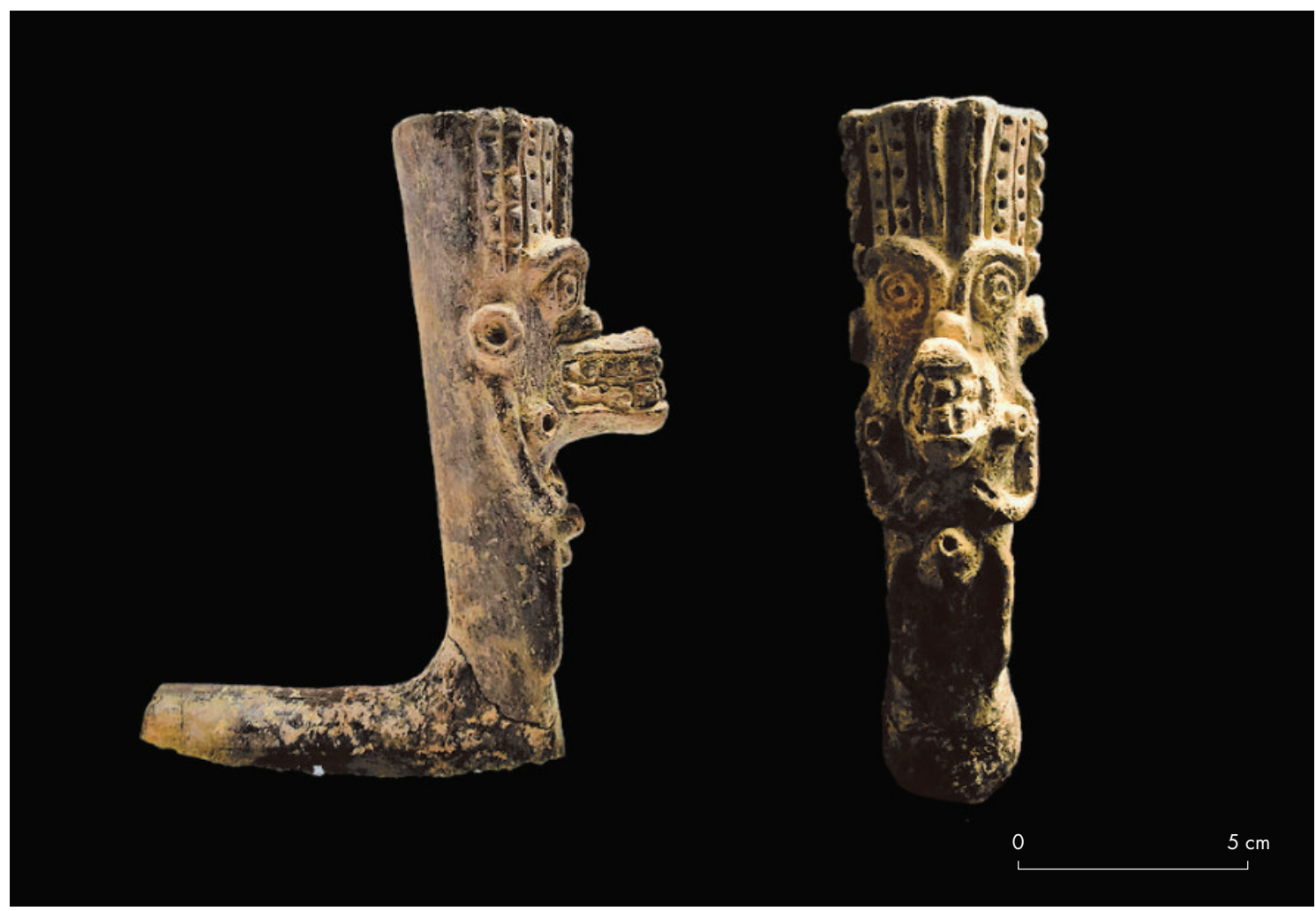

Figura 3. Ejemplar de pipa del sitio Arroyo Colorado. (Fotografías: G. Chauque). Figure 3. Pipe specimen from the Arroyo Colorado site. (Photographs: G. Chauque).

juvenil e infantil) (Ortiz et al. 2018). Además, se trata de un fogón muy potente, con una profundidad de 1,70 m y el único de esta clase excavado hasta el momento. En este mismo sitio registramos un solo caso de una pipa de piedra incompleta asociada a la inhumación de un individuo adulto masculino (Ortiz \& Nieva 2014; fig. 2 y tabla 1). Este entierro se encuentra espacialmente muy próximo al fogón en cuya periferia se recuperaron todos los ejemplares de pipas de cerámica.

En el sitio Moralito, las excavaciones realizadas durante tareas de rescate en la ejecución de la ampliación de un gasoducto interprovincial evidenciaron también una sectorización espacial para el hallazgo de estos artefactos. De acuerdo con la información proporcionada por quienes excavaron el sitio, fueron recuperados 52 fragmentos de pipas y un ejemplar casi completo en diferentes lugares a lo largo de una trinchera de $355 \mathrm{~m}$ lineales. La mayor cantidad de hallazgos se corresponde con dos sectores donde se concentran diversas clases de materiales contenidos en depresiones. Los investigadores interpretan estos sectores como recintos de habitación de tipo "casa pozo". En uno de ellos, de tamaño mayor a los demás identificados, habrían ocurrido actividades especiales, debido a la asociación con abundante cantidad de cerámica pintada, la que reviste una muy baja frecuencia en el conteo total de los materiales excavados (Echenique \& Kulemeyer 2003).

Finalmente, durante las tareas de ampliación de un sistema de riego en el sitio Arroyo Colorado, se recuperó un ejemplar de pipa que, posiblemente, pertenecía/correspondía a un enterratorio humano. El hallazgo no fue realizado ni registrado por personal profesional entrenado, por ello no podemos asegurar la asociación entre ambos eventos. Sin embargo, debido a la alta conservación del ejemplar, es posible que haya sido un objeto colocado junto con el difunto (tabla 1 , fig. 3). No obstante, estos artefactos no parecen haber formado parte del acompañamiento mortuorio, a diferencia de lo que ocurre en enterratorios del momento agroalfarero temprano en otras regiones del NOA, donde son frecuentes (Raffino 1977, Scattolin 2006, Fantuzzi 2008, Ledesma \& Subelza 2009). 


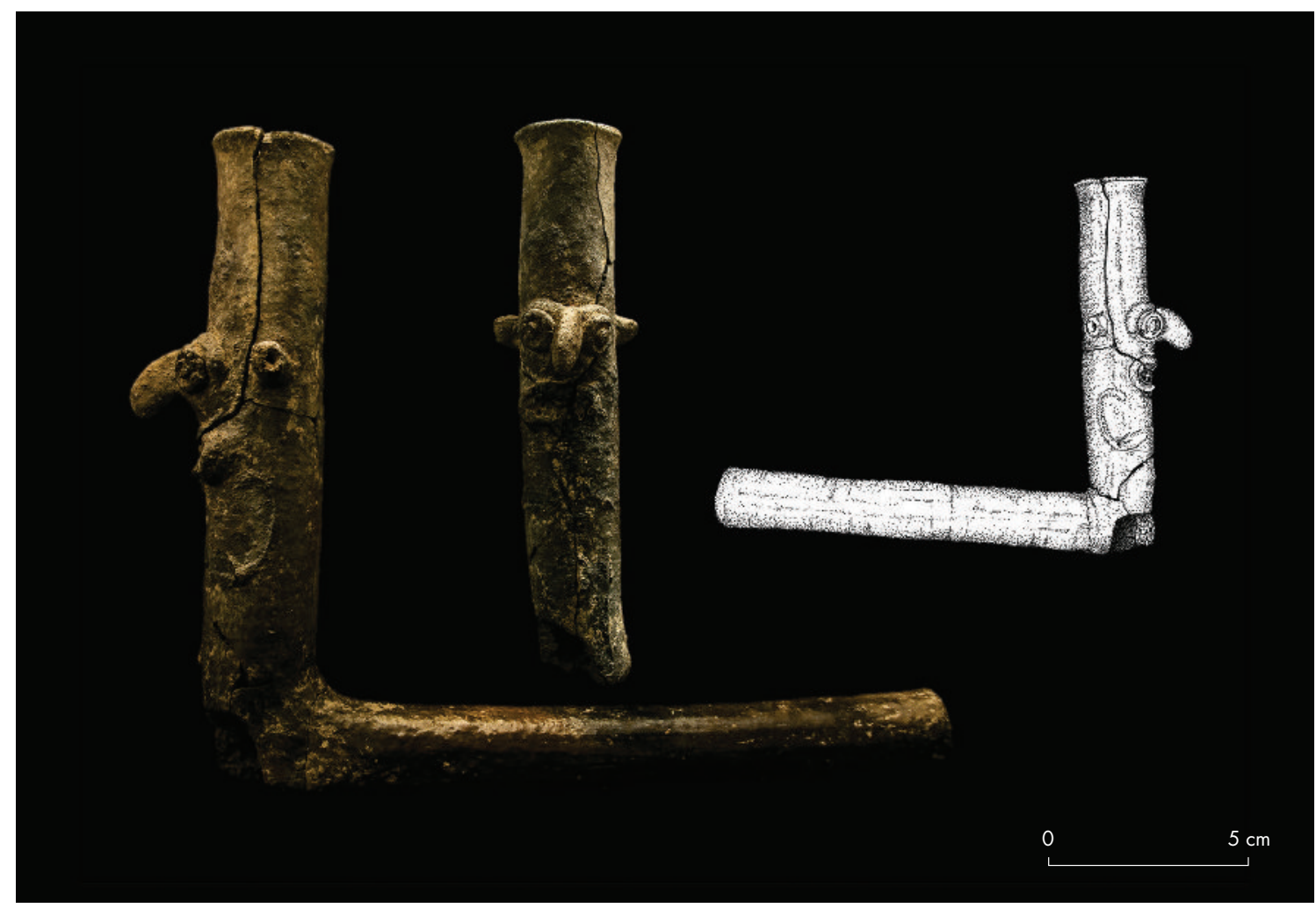

Figura 4. Pipa completa remontada del sitio Pozo de la Chola. (Fotografía: G. Chauque. Dibujo: L. Laguna). Figure 4. Complete pipe assembled from Pozo de la Chola site. (Photograph: G. Chauque. Drawing: L. Laguna).

Las características y la excepcionalidad de los espacios intrasitio donde han sido recuperados los ejemplares de pipas sugieren la presencia de ambientes de naturaleza ritual y singularizados. Por ejemplo, el tamaño del recinto y la vinculación con abundante cerámica pintada en el caso de Moralito, o la distribución alrededor de un gran fogón con evidencia de restos humanos quemados en su interior en Pozo de la Chola. Aunque desconocemos aún la estructura intrasitio en Pozo de la Chola, es sumamente sugerente la presencia de un gran fogón con restos humanos quemados, casualmente vinculado con la aparición de varios fragmentos de diferentes pipas y un ejemplar que pudo ser remontado en su totalidad (fig. 4).

Los análisis de residuo carbonizado en dos ejemplares de pipas permitieron conocer las especies botánicas utilizadas, que, en ambos casos, incluyen cebil (Anadenanthera colubrina), nicotiana (N. longiflora), Trichocline reptans y fibras afines al algodón (Lema et al. 2015) (tabla 1).

Las pipas se caracterizan morfológicamente por pertenecer al grupo de las denominadas angulares, algunas con apéndices a manera de patas en la unión tubo-rama horizontal. Tienen la particularidad de poseer un diámetro muy reducido en el sector medio del canal central interno (10 mm promedio), $y$ muchas de ellas exhiben un orificio basal en el ángulo de unión de ambas secciones. Técnicamente, parecen haber sido manufacturadas de manera muy similar, aunque pueden presentar diferencias en la morfología interna del hornillo. Exhiben comúnmente diseños antropomorfos y zoomorfos modelados en el hornillo, pero también se encuentran ejemplares sin agregados modelados. Los animales representados son principalmente aves (fig. 5). En muchos casos son sexuadas; con la particularidad de que se representa exclusivamente el sexo masculino y, en algunos casos, los genitales adquieren un elevado nivel de detalle. El modelado está ubicado frente al hornillo en posición opuesta al fumador (fig. 6).

Las pipas tienen diseños incisos al frente, vinculados con el hornillo. En ciertas ocasiones se modeló una especie de "tocado" proyectado sobre la cabeza y presentando diferentes detalles incisos o agregados al pastillaje. En algunas 
Tabla 1. Muestras de pipas de diversos sitios de tradición San Francisco. Referencias: NMI (número mínimo de individuos), F (fragmento), C (completa), PC (parcialmente completa), vSF (Valle de San Francisco), vJ (Valle de Jujuy), манрв (Museo Arqueológico e Histórico Pablo Baldwin). Los números entre paréntesis corresponden a cantidades absolutas. Table 1. Samples of pipes from different "San Francisco" tradition sites. References: NMI (minimum number of individuals), $F$ (fragment), C (complete), PC (partially complete), VSF (San Francisco Valley), vJ (Jujuy Valley), мАнрв (Archaeological and Historical Museum Pablo Baldwin). The numbers in parentheses correspond to absolute quantities.

\begin{tabular}{|c|c|c|c|c|c|c|c|}
\hline REGIÓN & SITIO & MINI & MATERIAL & $\begin{array}{c}\text { DECORACIÓN/ } \\
\text { AGREGADOS } \\
\text { PLÁSTICOS }\end{array}$ & $\begin{array}{l}\text { CONTEXTO } \\
\text { DE HALLAZGO }\end{array}$ & $\begin{array}{c}\text { TAXA } \\
\text { BOTÁNICAS }\end{array}$ & REFERENCIA \\
\hline VSF & $\begin{array}{l}\text { Pozo de la } \\
\text { Chola }\end{array}$ & $1(\mathrm{C})$ & Piedra & $\begin{array}{l}\text { Tubo con } \\
\text { incisión y } \\
\text { engrosamiento } \\
\text { en la unión } \\
\text { con el hornillo }\end{array}$ & Entierro & --- & $\begin{array}{l}\text { Ortiz \& Nieva } \\
2014\end{array}$ \\
\hline VSF & $\begin{array}{l}\text { Pozo de la } \\
\text { Chola }\end{array}$ & $11(\mathrm{~F})$ & Cerámica & $\begin{array}{c}\text { Antropomorfa } \\
\text { (1) } \\
\text { Fragmentos } \\
(10)\end{array}$ & Piso & --- & $\begin{array}{c}\text { Ortiz \& Nieva } \\
2014\end{array}$ \\
\hline VSF & Moralito & $\begin{array}{l}51(\mathrm{~F}) \\
1(\mathrm{PC})\end{array}$ & Cerámica & $\begin{array}{c}\text { Antropomorfa } \\
(1) \\
\text { Fragmentos } \\
(51)\end{array}$ & Piso & --- & $\begin{array}{c}\text { Echenique \& } \\
\text { Kulemeyer } 2003\end{array}$ \\
\hline VSF & $\begin{array}{l}\text { Fraile } \\
\text { Pintado }\end{array}$ & $1(\mathrm{PC})$ & Cerámica & Zoomorfa & $\begin{array}{l}\text { Desconocido } \\
\text { (rescate) }\end{array}$ & $\begin{array}{c}\text { Anadenanthera } \\
\text { colubrina } \\
\text { N. longiflora } \\
\text { Trichocline } \\
\text { reptans }\end{array}$ & Lema et al. 2015 \\
\hline VSF & Santa María & $3(\mathrm{C})$ & Cerámica & Zoomorfas & Desconocido & --- & $\begin{array}{c}\text { Colección MAнРв } \\
\text { Ortiz } 2007\end{array}$ \\
\hline VSF & El Quemado & $1(\mathrm{C})$ & Cerámica & Antropomorfa & Desconocido & --- & $\begin{array}{c}\text { Colección } \\
\text { particular Jujuy }\end{array}$ \\
\hline VSF & $\mathrm{A}^{\circ}$ Colorado & 2 & $\begin{array}{l}\text { Cerámica } \\
\text { Cerámica }\end{array}$ & $\begin{array}{l}\text { Con banda } \\
\text { al pastillaje } \\
\text { en la unión } \\
\text { hornillo/tubo } \\
\text { (1) } \\
\text { Antropomorfa } \\
\quad(1)\end{array}$ & $\begin{array}{l}\text { Desconocido } \\
\text { Desconocido } \\
\text { (rescate) }\end{array}$ & $\begin{array}{c}\text { Anadenanthera } \\
\text { colubrina } \\
\text { N. longiflora } \\
\text { Trichocline } \\
\text { reptans }\end{array}$ & $\begin{array}{l}\text { Ortiz 2007, Lema } \\
\text { et al. } 2015 \\
\text { Colección } \\
\text { Patrimonio } \\
\text { de Jujuy }\end{array}$ \\
\hline VSF & $\begin{array}{l}\text { Saladillo } \\
\text { Redondo }\end{array}$ & & Cerámica & --- & Desconocido & --- & Dougherty 1975 \\
\hline VJ & Palpalá & $2(\mathrm{C})$ & Cerámica & $\begin{array}{c}\text { Antropomorfa } \\
\text { (1) } \\
\text { Zoomorfa } \\
(1)\end{array}$ & Desconocido & --- & $\begin{array}{c}\text { Fernández et al. } \\
1999, \\
\text { Dougherty } 1975\end{array}$ \\
\hline VSF & El Infante & --- & Cerámica & --- & Piso & --- & Serrano 1962 \\
\hline VSF & $\begin{array}{l}\text { Aguas } \\
\text { Negras }\end{array}$ & $1(\mathrm{~F})$ & Cerámica & $\begin{array}{l}\text { Con banda } \\
\text { al pastillaje } \\
\text { en la unión } \\
\text { hornillo/tubo }\end{array}$ & Piso & --- & Ortiz 2007 \\
\hline
\end{tabular}


a
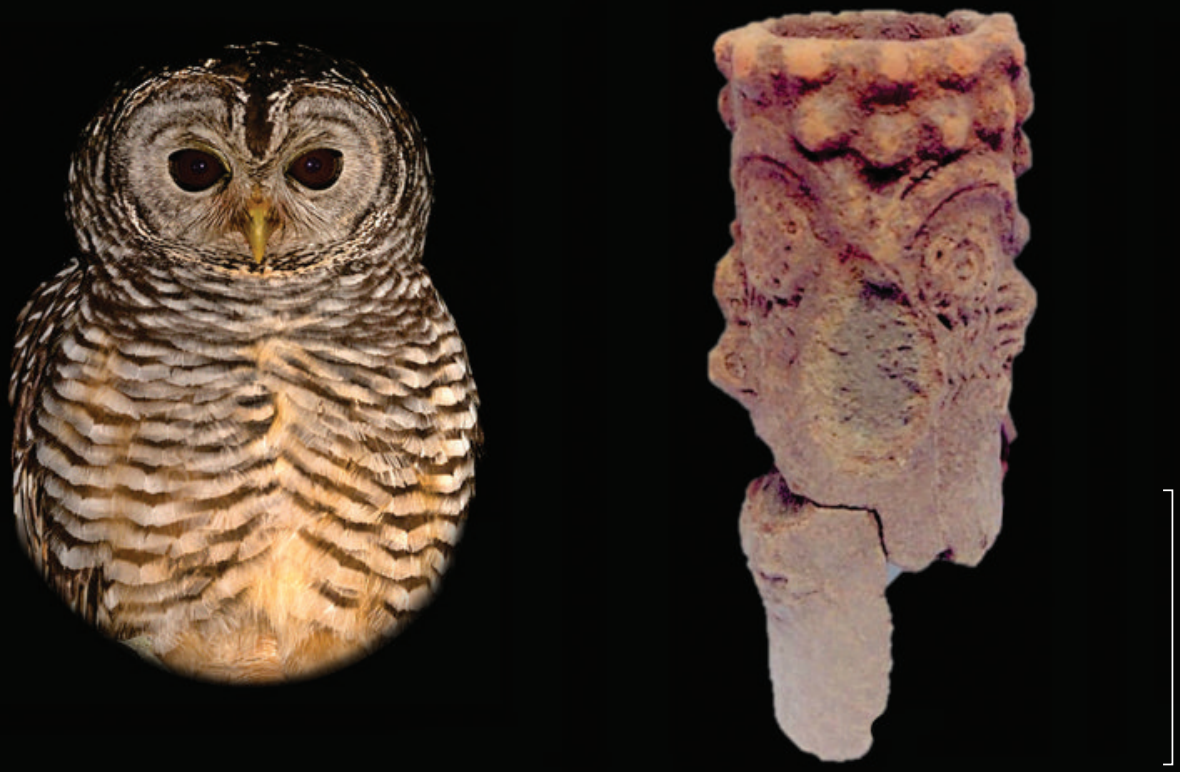

b
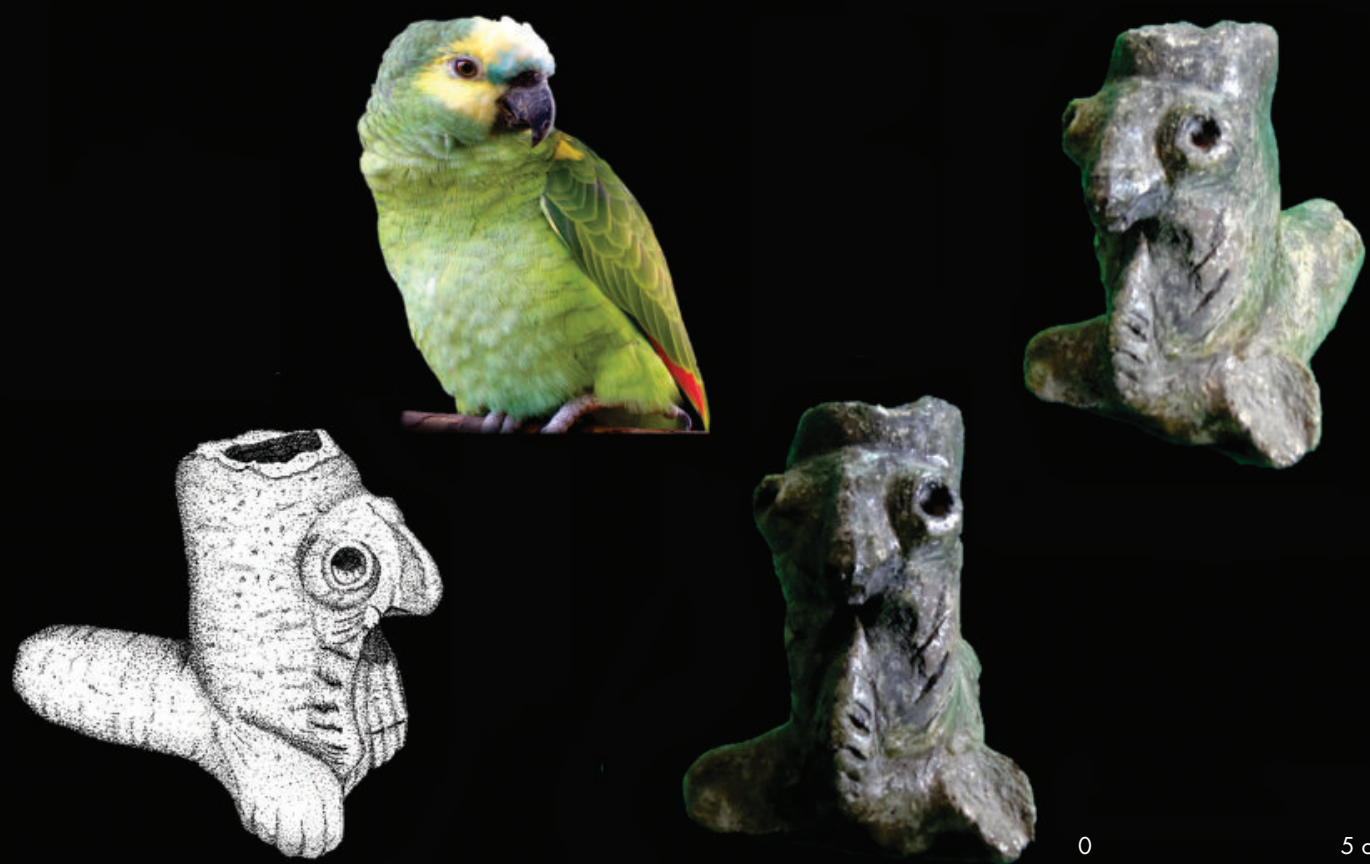

0

Figura 5. Ejemplares ornitomorfos: a) sitio Fraile Pintado, b) sitio Finca Santa María. Colección MAHPB, San Pedro de Jujuy. (Fotografías de los ejemplares: la autora; de lechuza y loro: Pablo Eguía. Dibujo: L. Laguna). <http://argentavis.org/2012/sitio/especie_id.php?id=697> $<$ http://www.loromania.com/amazonas.html> [consultado: 27-01-2020]. Figure 5. Ornithomorphic specimens. a) Fraile Pintado site. b) Santa María country estate. (Photographs of the specimens by the author. Drawing: L. Laguna. Photograph of owl and parrot: Pablo Eguía). <http://argentavis.org/2012/sitio/especie_id.php?id=697><http://www.loromania.com/amazonas.html> [accessed: 27-01-2020]. 


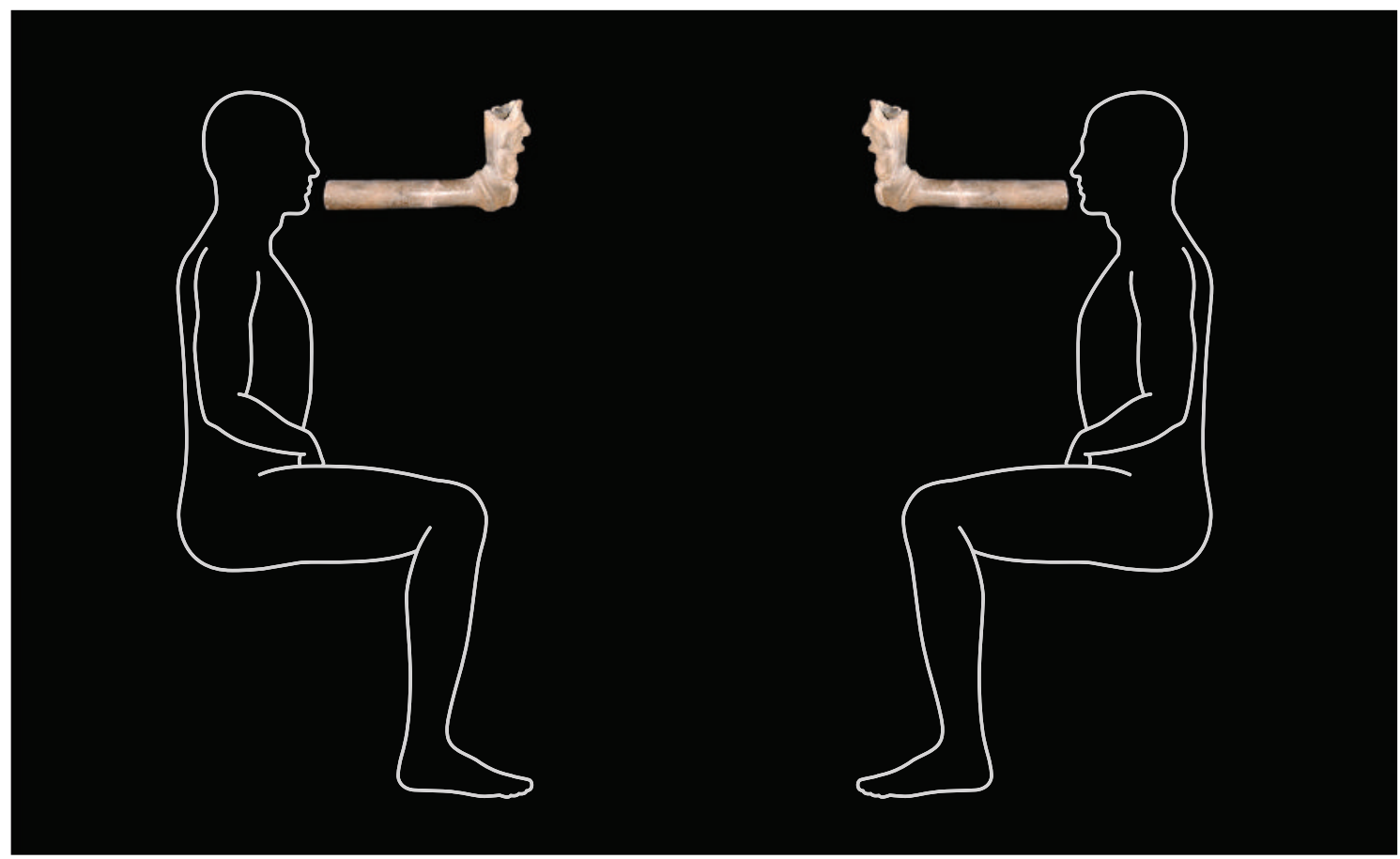

Figura 6. Representación de la posición de las pipas con el diseño modelado opuesto al fumador. (Fotografías y dibujo de la autora). Figure 6. Representation of the position of the pipes with modeled design opposite to the smoker. (Photographs and drawing by the author).

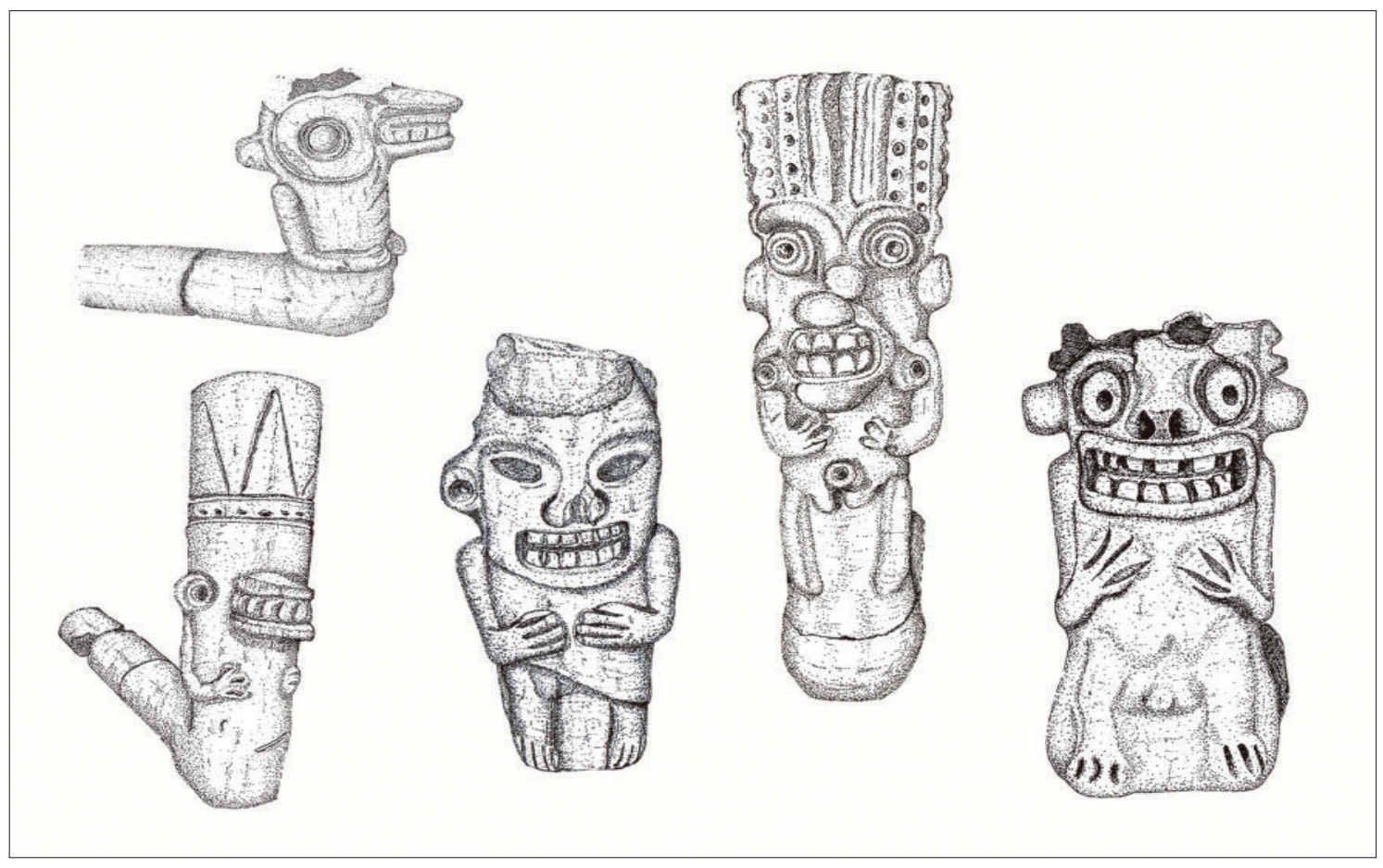

Figura 7. Distintos ejemplares de pipas. Nótese la posición de manos y piernas al frente (Dibujos: L. Laguna). Figure 7. Different specimens of pipes. Note the position of hands and legs in front (Drawing: L. Laguna). 

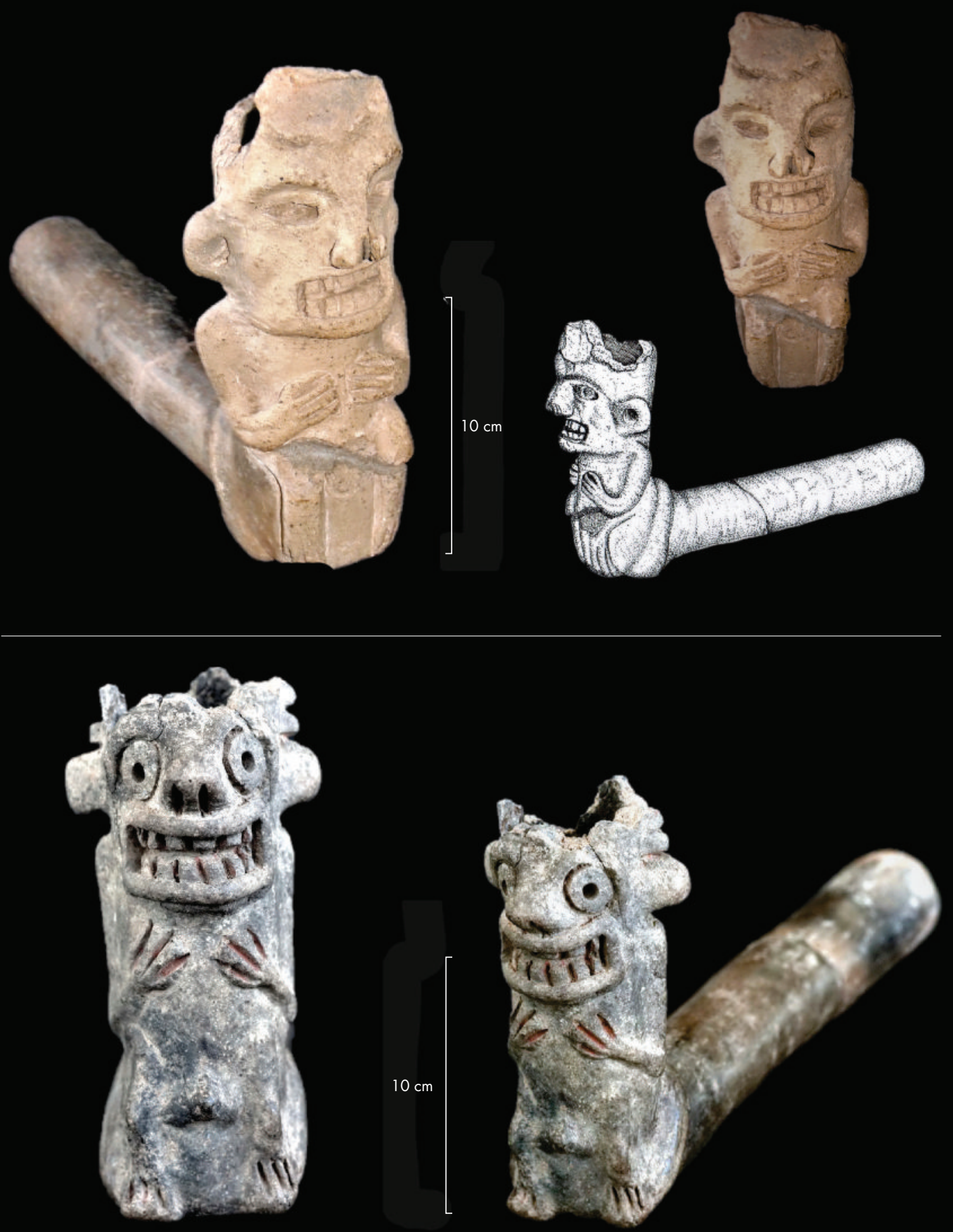

Figura 8. Posición sentada de los personajes representados. (Fotografías de la autora. Dibujo: L. Laguna). Figure 8. Sitting position of the individuals represented (Photographs by the author. Drawing: L. Laguna). 
se pudo verificar la presencia de pigmento rojo o blanco entre las incisiones. En otras, estas imágenes adquieren un carácter tridimensional que permite apreciar detalles referidos a la posición del cuerpo. Las antropomorfas exhiben una notable regularidad en el lenguaje corporal y en la localización y posición de los miembros superiores e inferiores, salvo aquellas que parecen encarnar animales. Los brazos son representados doblados con ambas manos abiertas colocadas sobre el pecho o a la altura del vientre y los dedos extendidos (fig. 7).

Los personajes aparecen sentados con ambas piernas dobladas por las rodillas en un ángulo de $90^{\circ}$. La relación proporcional y postural entre el cuerpo y las piernas sugiere que se encuentran sentados en alguna clase de soporte o banco (fig. 8). La boca de los personajes presenta usualmente forma antropomorfa cuadrangular y siempre exhiben los dientes (claramente humanos), estando ausentes las representaciones de colmillos. Incluso en aquellas que tienen atributos animales, los dientes son humanos, aunque se asocien a hocicos o fauces proyectadas hacia adelante.

\section{SHAMANES Y SERES AUXILIARES. HACIA UNA LECTURA DEL LENGUAJE CORPORAL}

El estudio de las pipas cerámicas, tanto en sus aspectos iconográficos como contextuales, han aportado datos novedosos. Como se ha destacado, las pipas de la región San Francisco comparten algunas características que las diferencian de otras encontradas en regiones aledañas. En primer lugar, presentan una regularidad notable en los gestos corporales. Los personajes están sentados, exhiben las manos abiertas sobre el pecho y las bocas o fauces abiertas mostrando dientes exclusivamente humanos. Al respecto, conviene considerar algunos aspectos.

En América, la posición sentada se asocia con la sabiduría o el poder, cualidades que no se excluyen. Algo que llamó la atención de numerosos conquistadores es que los personajes que detentaban algún rango, sea de naturaleza política o religiosa, podían tomar una postura sentada y, en muchos casos, poseer incluso bancos o soportes para colocarse en esa posición (Cobo 1979 [1653], Fernández de Oviedo 1959, Martínez 1988, Rosas 2009). Los bancos son concebidos como espacio de poder, de intercambio y de comunicación (Pineda Camacho 1993, 1994; Guinea 2004). Llamados dujos, duhos o duchos en las tierras bajas y tianas en la región andina, son considerados el eje del mundo, por lo tanto, solo pueden ser utilizados por aquellos con la consensuada autoridad social (Pineda 1994, Martínez 1988, Guinea 2004, Travassos \& Pahl 2011). El banco es símbolo de sabiduría, estabilidad y reflexión. Cuando alguien está sentado, está protegido por espíritus benevolentes y, en ese sentido, el banco es un objeto poderoso para chamanes, jefes y guerreros (McEwan 2001, Urbina 2003). Además, posee propiedades sociales como "espacio de autoridad, aura sagrada, recipiente de los dioses, fundamento de los muertos, medio de intercambio y considerados tesoro de los indios" (Pineda 1994: 9). Los personajes de las pipas, al ser representados en posición sentada, dan cuenta de su importancia, independientemente de que se trate de humanos o no humanos. Su postura comunica el lugar que ocupan y forma parte de un lenguaje simbólico tanto para el usuario como para un observador eventual. Más aún, los personajes no solo se encuentran sentados, sino que el asiento es la pipa misma (fig. 9).

La pipa sería así el axis mundi y cumpliría una doble función: oficiar de vehiculizador de los seres auxiliares que son representados en el modelado del hornillo y ser el asiento que permite la conexión y entrada al vagomundo. Aquí alcanzaría ontología propia al dejar de ser un mero objeto utilizado con cierta finalidad, para convertirse en el canal que intermedia la transposición del usuario adquiriendo vida propia en el transcurso del acto ritual. Un pasaje relatado por Zerrie en la década de 1970 es muy significativo respecto de la importancia de los asientos o bancos usados en las sesiones shamánicas:

En el transcurso de la fiesta, también los espíritus animales latentes en los bancos zoomorfos, en especial el demonio serpiente y el espíritu de la banqueta en forma de ave, recibían su parte de Kashiri que se prepara para esta ocasión, [...] al final se desanimaban nuevamente los objetos del culto; se desataban las fauces al banco en forma de sierpe, y el espíritu del brujo Wayapi ascendía nuevamente por sobre el extremo del mástil (Zerrie 1970: 294, en Pineda 1994).

Este pasaje es muy revelador, porque señala que las fauces esculpidas del animal son atadas como precaución y se le da de beber, esto significa que el banco adquiere vida a través de la presencia del shamán que oficia la ceremonia. Los espíritus viven en estado latente en los objetos, es decir, estos últimos tienen esencia y ontología propia. A su vez, los objetos no se encuentran alienados de un usuario, pues para "activarlos" requieren de un especialista capaz de convocar a los entes auxiliares que 


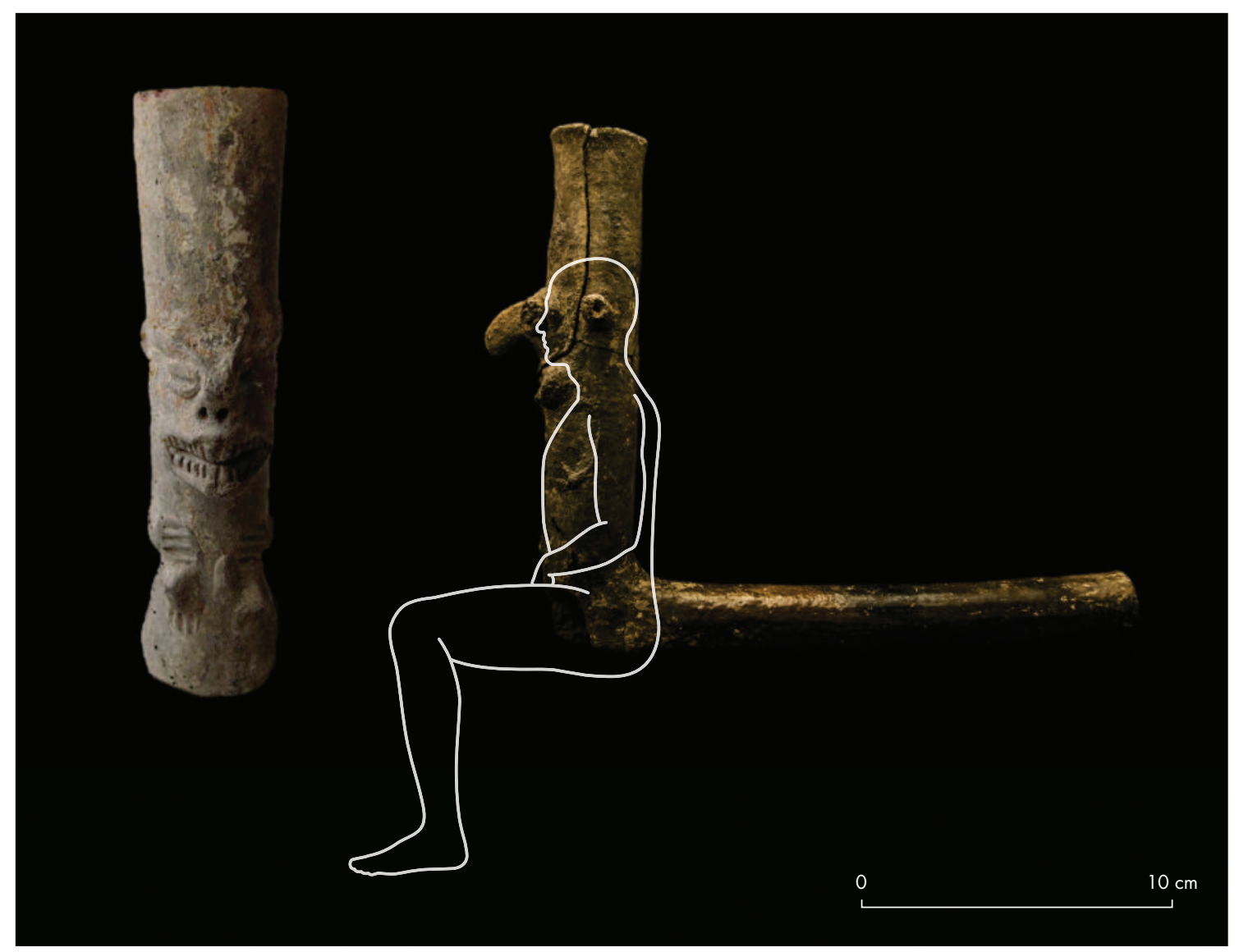

Figura 9. Representación de la posición del personaje en la pipa. (Fotografía izquierda: K. Garret, Colección del Museo de La Plata. A la derecha: fotografía y dibujo de la autora). Figure 9. Representation of the position of the figure on the pipe. (Photograph on the left: K. Garret, La Plata Museum Collection. Photograph and drawing on the right by the author).

los poseen. De esta manera, se establece una estrecha relación entre el shamán y el objeto al que interpela y es interpelado.

La segunda observación se refiere a la posición que adquieren las manos. Se trata de gestos recurrentes y repetitivos, por lo que no responderían a una ejecución libre del artesano. Existen numerosos estudios sobre las acciones gestuales, especialmente de las manos, como símbolos comunicacionales. En diversas tradiciones, los gestos hechos con manos y brazos se utilizan para comunicar mensajes codificados particulares, a menudo de gran complejidad (Ancona-Ha et al. 2000). Es decir, la atención prestada a la representación de un gesto específico en la elaboración del artefacto, debió responder a la intención de comunicar un significado especial susceptible de ser interpretado por aquellos que estuvieran familiarizados con su convención. Diferentes trabajos dan cuenta de la importancia comunicacional de los gestos asociados con esta clase de lenguaje no verbal en América. Por ejemplo, extender los brazos con las manos abiertas y las palmas hacia afuera mientras se sopla en dirección del divinizado, era el acto final que sellaba la entronización del kuraka en los Andes (Martínez 1988); los puños cerrados con el pulgar hacia adelante solo se encuentran representados en los personajes sentados que personalizan a la élite y a los shamanes en la cultura Manteño-Huancavilca (Guinea 2004); y las diversas posiciones de las manos en el arte maya operaron como señales de jerarquías y rangos sociales específicos (Ancona-Ha et al. 2000).

No hemos encontrado información exacta sobre la posición de las manos de la forma en la que fueron representadas en las pipas; no obstante, su repetición recurrente y consistente en numerosos artefactos nos 
permite suponer que este gesto tuvo un significado específico. Como ha sido representado solo en las pipas y no en otro tipo de artefactos con modelados, creemos que se trataría de alguna clase de acción gestual que operaría como una especie de lenguaje vehiculizador de los auxiliares invocados.

Los seres representados en las pipas son siempre varones. Esto proporciona información acerca de los usuarios y, posiblemente, de la esfera de género con que se vincula el uso de estos artefactos. Si los entes representados pertenecen al dominio masculino, se puede deducir claramente una asimetría de género en la cual las mujeres podrían estar exentas de su uso. Si shamanes y seres auxiliares no pueden ser disociados, ya que los primeros se convierten en los segundos, o pueden ser acompañados por aquellos en los viajes al vagomundo, es poco probable que una mujer pudiera usar una pipa de esta clase, ya que los seres auxiliares se asocian al ámbito masculino.

Vinculado con la naturaleza ritual de esta clase de objetos, observamos que cumplen con aquellas condiciones individualizadas por Walker al referirse a las características de los artefactos que forman la "basura ritual". En primer lugar, están restringidas al intercambio. Los estudios iconográficos, morfológicos o de composición de pasta prueban que las pipas, en general, son producidas y usadas localmente, lo que indica su singularidad (Ortiz 2015, Cremonte et al. 2016). Esta es una de las principales características de los artefactos que son eliminados de las esferas de intercambio (Appadurai 1986, Gell 1986). Además, sobre la base de su distribución espacial intrasitio, podemos decir que fueron depositadas o descartadas en espacios discretos que corresponderían a lugares sociales de importancia simbólica (recintos de uso especial o espacios asociados con rituales post mórtem).

Considerando que la gran mayoría corresponde a piezas rotas o fragmentos, es posible asumir que habían concluido su vida útil. No se han registrado dos ejemplares idénticos de pipas hasta el momento. La razón más probable es que su manufactura dependía de la función a la que estaba destinada, es decir, a particulares agentes auxiliares asociados con la práctica shamánica y con usuarios individuales. Según Walker "los artefactos en depósitos de basura ceremonial han finalizado su vida útil como resultado del desgaste o se han vuelto obsoletos porque sus usuarios han muerto" (Walker 1995: 75 , traducción de la autora). Si los entes auxiliares eran vehiculizados por intermedio de las pipas y solo el sha- mán podía invocarlos, una vez que el usuario moría las pipas habrían sido descartadas o incluso rotas ex profeso. Esto podría explicar el hallazgo inusual de un ejemplar fracturado que pudo ser remontado completamente en Pozo de la Chola o de uno parcialmente completo en Moralito. En el caso del fragmento de rama horizontal de la pipa de piedra recuperada en Pozo de la Chola, es interesante que haya sido colocada como acompañamiento mortuorio, a pesar de tratarse de un ejemplar roto. Destruir los objetos que, se supone, tienen particulares energías, es una práctica recurrente y documentada tanto en contextos etnográficos y arqueológicos como una manera de neutralizar su poder y los potenciales efectos negativos; o cuando formaban parte de ofrendas sacrificiales (Cook 1984-1985, Kolata 1993, Walker 1995, Perrín 2005). Igualmente, colocarlas en las tumbas es otra forma de eliminar el objeto tanto de la esfera de uso como de la del intercambio, es decir, tienen historias de vida muy controladas como artefactos rituales.

\section{A MANERA DE SÍNTESIS}

Las pipas utilizadas por los grupos pedemontanos del Formativo de Jujuy pueden ser consideradas una tecnología ritual (Walker 1995). Se trataría de objetos sacralizados y como tal cumplen con una serie de pasos en su ciclo de vida antes de convertirse en basura ritual. Tienen características comunes, como estar singularizadas al ser eliminadas de las esferas de intercambio y ser depositadas en espacios discretos únicos e irrepetibles. El lugar físico donde suele descartarse la basura ceremonial tiene también connotaciones especiales.

En los casos presentados en este artículo, las pipas o sus fragmentos aparecen en espacios particulares intrasitio. En Moralito se las encontró asociadas a un recinto con características distintivas -sobre la base de su tamaño y la presencia de otros materiales cerámicos de muy baja frecuencia en el conteo total del sitio-, y en Pozo de la Chola dispuestas alrededor de un gran fogón en cubeta con restos humanos quemados, estando ausentes hasta el momento en otros sectores excavados del sitio arqueológico.

Por otra parte, la particular iconografía daría cuenta de algunas claves visuales redundantes. Cada pipa es única e irrepetible, pero a su vez, los personajes representados exhiben una notable regularidad en los gestos corporales. Sobre la base de la abundante infor- 
mación etnográfica, podríamos suponer que esta clase de objetos se vincularía a "seres auxiliares", quienes acudirían en apoyo del shamán al realizar los rituales. Los seres representados en los hornillos de las pipas miran siempre en dirección opuesta al fumador, razón por la cual asumimos que, aunque estén directamente relacionados entre sí, la interacción comunicacional visual no es destinada al usuario. Es probable que la relación comunicacional sea con el cosmos mismo, si se trata de un artefacto vehiculizador tanto de los entes que acudirían a las sesiones como del shamán en su viaje a otros niveles de existencia. Los seres zoomorfos representados en las pipas pertenecen al mundo de las aves, estando totalmente ausente la imagen del felino. Es importante destacar que para las poblaciones del Chaco las aves encarnan la mayoría de los mitos (Dasso \& Barúa 2006, Ottalagano 2007, Alvarsson 2012). El relato de una ceremonia de inhalación de cebil por parte de los wichis del Chaco argentino ilustra la relación entre aves y elementos vehiculizadores:

Transcurridas unas vueltas en torno de la mesa y los demás participantes, el shamán irá haciendo sonar el tohúl (flauta de hueso de Yulo) ${ }^{4}$ con largos silbidos separados por silencios, siendo seguido sucesivamente por lo demás. El alma del shamán se cree que sale por el tohúl, que posibilita su desprendimiento y ascenso, donde se mete en el ave que le permitirá volar y ver el mundo desde esta perspectiva aérea (Dasso \& Barúa 2006: 222, destacado de la autora).

Finalmente, la tecnología ritual está presente toda vez que se necesita restituir el equilibrio ante cualquier situación de entropía. Esta puede vincularse tanto a situaciones particulares como a toda una comunidad, en cuyo caso las ceremonias suelen incluir varios shamanes poderosos, cada uno con su parafernalia personal, quienes trabajan mancomunadamente para contrarrestar el origen y los efectos negativos de cualquier situación considerada anómala y potencialmente peligrosa para el equilibrio social (Califano 1976, Alvarsson 2015).

Agradecimientos A Beatriz Ventura por los comentarios al borrador y a María Zaburlin por sus atinadas observaciones. A los alumnos de la FHyCS de la unju que colaboraron en los trabajos de campo. A Guillermo Chauque por las fotografías que ilustran las figuras 3 y 4 . Al licenciado Luis Laguna, por los dibujos de las pipas en blanco y negro. A los directivos del Ingenio Azucarero La Esperanza, de la ciudad de San Pedro de Jujuy, por su apoyo logístico. Estas investigaciones fueron realizadas en el marco del proyecto SECTER C/175 de la unju.

\section{NOTAS}

${ }^{1}$ Es el período por el que atraviesa todo aprendiz de shamán. Incluye diversos ayunos, consumo reiterado de alucinógenos, sueños visionarios, aparición de seres sobrenaturales que luego serán los ayudantes en diferentes situaciones y procedimientos, y períodos de abstinencia y aislamiento. Suele durar muchos años y concluye una vez que el individuo o su mentor consideran que el aprendizaje se ha completado.

2 "El vagomundo, propio de chamanes legítimos, se puede definir como acciones intencionales y efectivas consideradas reales en un mundo alucinado considerado como real. De esto se deriva que el vagomundo sea una entidad ontológica, dotada de un orden mítico arbitrario relativo al sujeto chamán” (Ogalde 2007: 77). Es lo que algunos etnógrafos describen como "trance", donde el shamán nunca experimenta amnesia, por el contrario, recuerda con detalle la experiencia vivida y le otorga sentido e inteligibilidad (Chaumeil 1998, Descola 2005).

${ }^{3}$ Neologismo acuñado por Wasson et al. 1985. Significa "volverse divino interiormente" o "Dios dentro de nosotros", como una forma de diferenciar el verdadero significado de la experiencia vinculada generalmente con la noción de "estado alterado de conciencia”, inducido por la vivencia alucinógena. Los autores argumentan que los términos psicodélico, alucinógeno o psicotomimético no dan cuenta del verdadero significado, uso y valor asociado a los vegetales consumidos, ni de la experiencia derivada de ello.

${ }^{4}$ Se refiere a la cigüeña Jabiru mycteria.

\section{REFERENCIAS}

Alvarsson, J. 2012. Héroes y pícaros. Introducción al mundo mítico. Estocolmo: Universidad de Uppsala.

Alvarsson, J. 2015. De armonía a fuerza. La religión en una perspectiva diacrónica. Estocolmo: Universidad de Uppsala.

Ancona-Ha, P., Pérez, J. \& Van Stone, M. 2000. Some observations on hand gestures in Maya Art. En The maya vase book: a corpus of rollout photographs of maya vases, Volumen VI, J. Kerr, Ed., pp. 1072-1089. NuevaYork: Kerr Associates.

APPADURAI, A. 1986. Introducción: las mercancías y la política del valor. En La vida social de las cosas. Perspectiva cultural de las mercancías, A. Appadurai, Ed., pp. 17-88. Ciudad de México: Grijalbo.

Bourdieu, P. 1980. El sentido práctico. Buenos Aires: Siglo XXI.

Bovisio, M. A. 2012. La metáfora como principio estético en el arte prehispánico del Noroeste Argentino. Boletín do Museo Paranaense Emílio Goeldi 7 (1): 161-178.

Bugliani, M. F., Calo, C. M. \& Scattolin, M. C. 2010. Fumando en la cocina. Determinación de contenidos por técnicas fisicoquímicas en dos pipas cerámicas del sitio 
Cardonal. En La arqueometría en Argentina y Latinoamérica, S. Bertolino, R. Cattáneo \& A. D. Izeta, Eds., pp. 231-236. Córdoba: Universidad Nacional de Córdoba.

Califano, M. 1976. El chamanismo mataco. Scripta Sthnologica 3 (2): 7-60.

Capparelli, A., Pochettino, M. L., Andreoni, D. \& ItUrriza, R. 2006. Differences between written and archaeological record. The case of plant micro remains recovered at a Northwestern Argentinean pipe. Proceedings of the IVth International Congress of Ethnobotany (ІСЕВ 2005), Z. Füsun Ertuğ, Ed., pp. 397-406. Estambul: Yeditepe University.

Chaumeil, J. P. 1998. Ver, saber, poder. Chamanismo de los yagua de la Amazonía peruana. Lima: IFEA, CAEA.

Chaumeil, J. P. 2005. Un método de asimilación. Sobre la noción de transformación en unas culturas sudamericanas. En Chamanismo y sacrificio. Perspectivas arqueológicas y etnológicas en sociedades indígenas de América del Sur, J. P. Chaumeil, R. Pineda Camacho \& J. F. Bouchard, Eds., pp. 165-176. Bogotá: IFEA.

Cremonte, M. B., Pereira, L. \& Scaro, A. 2016. San Francisco, pastas cerámicas de una tradición alfarera de las yungas jujeñas. En Entre la vertiente tropical y los valles. Sociedades regionales e interacción prehispánica en los Andes Centro-Sur, S. Alconini, Ed., pp. 241-263. La Paz: Plural.

Сово, В. 1979 [1653]. Inca religion and customs. Austin: University of Texas Press.

Cook, A. 1984-1985. The Middle Horizont ceramic offering from Conchopata. Ñawpa Pacha 22-23: 49-90.

Dasso, M. C. \& BArúA, G. 2006. El devenir de bienes e instituciones: el cebil y el shamanismo wichi. En Pueblos y culturas de las Américas: diálogos entre globalidad y localidad. Archivos Departamento de Antropología Cultural, Centro de Investigaciones en Antropología Filosófica y Cultural de la Asociación Argentina de Cultura, Eds., IV, 1, pp. 219-248. Buenos Aires: CIAfIC.

Descola, P. 1986. La nature domestique. Symbolisme et praxis dans lécologie des Achuar. París: Editions de la Maison des Sciences de l'Homme.

Descola, P. 2005. Las lanzas del crepúsculo. Relatos jíbaros. Alta Amazonía. México DF: Fondo de Cultura Económica.

Descola, P. 2012. Más allá de naturaleza y cultura. Buenos Aires: Amorrortu.

Dougherty, B. 1975. Nuevos aportes para el conocimiento del Complejo Arqueológico San Francisco (sector septentrional de la región de las selvas occidentales argentinas, subárea del Noroeste Argentino). Tesis para optar al grado de Doctor en Ciencias Naturales, Universidad Nacional de La Plata, Argentina.

Echenique, M. \& Kulemeyer, J. 2003. La excavación arqueológica de una "mancha blanca", el sector M43C en el sitio Moralito, Departamento San Pedro, Provincia de Jujuy (República Argentina). En La mitad verde del mundo andino. Investigaciones arqueológicas en la vertiente oriental de los Andes y las tierras bajas de Bolivia y Argentina, G.
Ortiz \& B. Ventura, Eds., pp. 99-132. San Salvador de Jujuy: EDIUNJU.

FAntuzZI, L. 2008. Análisis de las prácticas funerarias en el sector sur de la necrópolis de La Ciénaga (Prov. de Catamarca, Argentina). La Zaranda de Ideas 4: 55-75.

FERnÁNDEZ, A. 1980. Hallazgo de pipas en complejos precerámicos del borde de la puna jujeña (República Argentina) y el empleo de alucinógenos por parte de las mismas culturas. Estudios Arqueológicos 5: 55-59.

Fernández, A., Raviña, M. G. \& Balesta, B. 1999. Las pipas precolombinas del norte argentino. Buenos Aires: Academia Nacional de Historia.

Fernández de Oviedo, G. 1959 [1549]. Historia general y natural de las Indias. Madrid: La Real Academia de Historia.

Flores, M. G. \& EchAzú, A. G. 2016. Ontologías en desigualdad: coca, ayahuasca y la agencia histórica. Avá 29: 155-174.

GeLL, A. 1986. Los recién llegados al mundo de los bienes. El consumo entre los gondos muria. En La vida social de las cosas. Perspectiva cultural de las mercancías, A. Appadurai, Ed., pp. 143-178. México DF: Grijalbo.

Gili, F., Echeverría, J., Stovel, E., Deibel, M. \& Niemeyer, H. M. 2017. Las pipas del salar de Atacama: reevaluando su origen y uso. Estudios Atacameños 54: 37-64.

Gonzalo, J. 1998. La cultura material de los mataco (MatacoMaka) del Chaco central. Buenos Aires: Mankacén.

GuineA, M. 2004. Los símbolos del poder o el poder de los símbolos. En Simbolismo y ritual en los Andes Septentrionales, M. Guinea, Ed., pp. 9-52. Quito: Complutense.

Kolata, A. 1993. The Tiawanaku. A portrait of an andean civilization. Cambridge: Wiley Blackwell Pub.

Ledesma, R. \& Subelza, C. 2009. Alcances y limitaciones para caracterizar las ocupaciones formativas en Cafayate (Salta). Andes 1 (20): 75-109. <https://www.academia. edu/29424774/Alcances_y_Limitaciones_Para_Caracterizar_Las_Ocupaciones_Formativas_en_Cafayate_Salta_> [consultado 26-01-2020].

Lema, V. 2017. Del objeto al contexto: la(s) capa(s) "E" de Huachichocana III. Chungara 49 (2): 209-226.

Lema, V., Andreoni, D., Capparelli, A., Ortiz, G., Spano, R., Quesada, M. \& ZorZI, F. 2015. Protocolos y avances en el estudio de residuos de pipas arqueológicas de Argentina. Aportes para el entendimiento de metodologías actuales y prácticas pasadas. Estudios Atacameños 51: 77-97.

Martínez, J. L. 1988. Kurakas, rituales e insignias: una proposición. Histórica XII (1): 61-74.

McEwan, C. 2001. Seats of power: axiality and access to invisible worlds. En Unknown Amazon. Nature and culture in ancient Brazil, C. McEwan, C. Barreto \& E. Neves, Eds., pp. 176-195. Londres: British Museum Press.

Montani, R. 2013. La construcción material de la persona entre los wichís del Gran Chaco. Avá 22: 167-190. <https:// www.researchgate.net/publication/299894154_La_construccion_material_de_la_persona_entre_los_Wichis_del_ Gran_Chaco> [consultado: 16-09-2018]. 
Morales, S. 2014. Sobre objetos que vuelan en el cosmos. Crítica al perspectivismo amerindio de Eduardo Viveiros de Castro. Patio de Sociales: 18-36.

Nielsen, A., Angiorama, C. \& Ávila, F. 2017. Ritual as interaction with non-humans: prehispanic mountain pass shrines in the Southern Andes. En Rituals of the past. Prehispanic and colonial case studies in Andean Archaeology, S. Rosenfeld \& E. Bautista, Eds., pp. 241-266. Colorado: University Press of Colorado.

NikLison, J. E. 1990 [1916]. Los tobas. San Salvador de Jujuy: EDIUNJU.

OGALDE, J. P. 2007. El vagomundo del chamán: epistemología de la praxis psicotrópica chamánica. Diálogo Andino 29: 75-90.

Ortiz, M. G. 2003. Estado actual del conocimiento del denominado Complejo o Tradición San Francisco, a 100 años de su descubrimiento. En La mitad verde del mundo andino. Investigaciones arqueológicas en la vertiente oriental de los Andes y las tierras bajas de Bolivia y Argentina, G. Ortiz \& B. Ventura, Eds., pp. 23-68. San Salvador de Jujuy: EDIUNJu.

Ortiz, M. G. 2007. La evolución del uso del espacio en las tierras bajas jujeñas (subárea del río San Francisco). Tesis para optar al grado de Doctora en Arqueología, Universidad Nacional de Córdoba, Córdoba, Argentina.

Ortiz, M. G. 2015. Avances y nuevas perspectivas en la arqueología del piedemonte de Jujuy (valle de San Francisco), Argentina. En En el corazón de América del sur 3. Arqueología de las tierras bajas de Bolivia y zonas limítrofes, S. Alconini \& C. Jaimes, Eds., pp. 195-212. Santa Cruz de la Sierra: Biblioteca del Museo de Historia.

Ortiz, M. G. \& Nieva, L. 2014. Morir en el valle de San Francisco. Prácticas funerarias, termoalteración y estrategias de memorización en la selva pedemontaña de las Yungas del Noa. Zeitschrift für Archäologie aussereuropäischer Kulturen 6: 247-276.

Ortiz, M. G., Paz, F., Zenteno, B., Zuñiga, S. \& Nieva, L. 2018. Estudio de sub-adultos de la cuenca del río San Francisco, Provincia de Jujuy, Argentina (0-500 DC). Revista Argentina de Antropología Biológica 20 (2): 1-15.

Ottalagano, F. V. 2007. Algunas referencias en torno al simbolismo de las aves en los registros etnohistóricos y etnográficos de guaycurúes y mataco-mataguayos. Arqueología Suramericana 3 (2): 213-228.

Pérez, J. \& Gordillo, I. 1995. Alucinógenos y sociedades indígenas del Noroeste de Argentina. Anales de Antropología 30: 299-350.

Perrín, M. 2005. ¿Unos objetos chamánicos sacrificados? En Chamanismo y sacrificio. Perspectivas arqueológicas y etnológicas en sociedades indígenas de América del Sur, J. P. Chaumeil, R. Pineda \& J. F. Bouchard, Eds., pp. 201223. Lima: IFEA.

Pineda, R. 1993. El butaquito amerindio. Un verdadero Aleph para el pensamiento. Innovación y Ciencia 2: 39-42.
Pineda, R. 1994. Los bancos tamaturgos. Boletín del Museo del Oro 36: 3-41.

Raffino, R. 1977. Las aldeas del Formativo Inferior de la Quebrada del Toro. Estudios Atacameños 5: 65-109.

Reynoso, C. 2015. Crítica de la antropología perspectivista (Viveiros de Castro-Philippe Descola-Bruno Latour). Buenos Aires: SB.

RosAs, C. 2009. Entre la satanización y la idealización. La figura del curaca en la historiografía andina contemporánea. Histoire(s) de l'Amérique Latine 3: 1-36.

Rosso, C. \& Spano, R. 2005-2006. Humos del vecino: evidencias del uso de alucinógenos en pipas halladas en dos sitios tempranos de los Valles Calchaquíes. Arqueología 13: 79-98.

Scattolin, M. C. 2006. De las comunidades aldeanas a los curacazgos en el Noroeste Argentino. Boletín de Arqueología PUCP 10: 357-398.

SERrANo, A. 1962. Investigaciones arqueológicas en el valle del río San Francisco (Prov. de Jujuy). Salta: Salesianos.

Travassos, D. \& PAHL, D. 2011. Os bancos de cerâmica marajoara: seus contextos e possíveis significados simbólicos. Amazônica 3 (1): 108-141.

Torres, C. M. \& Repke, D. 1996. The use of Anadenanthera colubrina var. Cebil by Wichi (Mataco) shamans of the Chaco Central, Argentina. Jahrbuch für Ethnomedizin 1996: 41-58.

Urbina, F. 2003. Las poses del sabedor. La Taddeo 68: 88-96.

VILAçA, A. 2005. Chronically unstable bodies: reflections on amazonian corporalities. Royal Anthropological Institute 11: 445-464.

Viveiros de CAstro, E. 2004. Perspectivismo y multinaturalismo en la América indígena. En Tierra adentro. Territorio indígena y percepción del entorno, A. Surrallés \& P. García Hierro, Eds., pp. 37-82. Copenhague: IWGIA.

WALKer, W. 1995. Ceremonial trash? En Expanding archaeology, J. Skibo, W. Walker \& A. Nielsen, Eds., pp: 67-79. Ciudad del Lago Salado: University of Utha Press.

Wasson, R. G., Hofmann, A. \& Ruck, C. A. 1985. El camino a Eleusis. Una solución al enigma de los misterios. México: Fondo de Cultura Económica. 